\title{
D. LUIS CIFUENTES EN MI RECUERDO
}

\author{
Francisco Pastor Sempere.
}

Servicio de Urología. Hospital de Sagunto. Valencia. España.

Resumen.- Glosar la figura del maestro D. Luis Cifuentes Delatte en sus vertientes científica y humana, desde el emotivo recuerdo de un discípulo agradecido.

Palabras clave: Litogénesis. Cistopatia. Tumor vesical. Luis Cifuentes Delatte.
Summary.- To gloss the figure of Professor Dr. Luis Cifuentes Delatte in both his scientific and human features, from the emotional memory of a grateful disciple.

Keywords: Lithogenesis. Cystopathy. Bladder tumor. Dr. Luis Cifuentes Delatte.

\section{INTRODUCCIÓN}

Acepté con ilusión y agradecimiento la invitación de José Luis Rodríguez-Miñón Cifuentes a participar en este número extraordinario de Archivos Españoles de Urología, destinado a glosar la figura de uno de sus fundadores, D.Luis Cifuentes Delatte. Y nada más aceptar me pregunté qué podría yo contar a los urólogos de mi generación sobre la dimensión científica de D. Luis, de sobra conocida por todos, y a los urólogos más jóvenes, dado que su legado bibliográfico ha sido bien difundido. No podemos olvidar la reciente monografía publicada en Actas Urológicas Españolas, donde significados discípulos del Dr. Cifuentes glosan aspectos de su vasta producción científica.

Aún así, pensé que me podía permitir bosquejar algunos aspectos doctrinales de sus líneas de trabajo, a lo largo de su dilatada vida científica, que para mí fueron trascendentales, y que gracias a su proverbial claridad hoy continúan de plena actualidad.

Un ejemplo claro es su mundo de la litogénesis, ese mundo del que los urólogos generales de hoy parece que nos hayamos olvidado, mereció para $D$. 
Luis una atención constante, aportando conocimientos inéditos, tanto en petrografía como en el conocimiento de la litiasis infectiva, su "Corynebacterium urealyticum".

También es obligatorio recordar sus aportaciones sobre las Lesiones Neurológicas Vesicales. Nadie de mi generación habrá olvidado su ponencia sobre Vejiga Neurógena en el Congreso Nacional de Urología de 1966 en Zaragoza. En aquellos tiempos, fue para nosotros una de las pocas armas a nuestro alcance en esta materia, con conceptos fisiopatológicos claros y comprensibles.

Personalmente mis preferencias sobre la obra de D. Luis se centraron en la vejiga y en la próstata, tanto en el estudio y concepción de las Cistopatías y del Tumor Vesical como en su tratamiento. En 1966 hablar de Resección Transuretral en España era una fantasía de ilustrados, pero en la Clínica de la Concepción era una realidad, como lo es en la actualidad en cualquiera de nuestros modernos hospitales.

Eso sí, entonces los medios técnicos de que disponíamos eran auténticamente rudimentarios: iluminación por lámpara incandescente, falta de corriente contínua de lavado y ausencia total de dispositivos de enseñanza. Como bien se comprende, en estas circunstancias la RTU para el ayudante era un auténtico acto de fe. Estabas al lado del cirujano, con el colador en la mano, esperando recolectar los fragmentos resecados y cuando se te invitaba a mirar por la óptica tan solo veías un círculo rojo, donde no era posible reconocer nada.

Con la incorporación de la luz fría, la corriente contínua y las ópticas de enseñanza, los residentes comenzamos a convertir ese acto de fe en realidad palpable. Mucho fue lo que nos ayudó el fantomas improvisado (una especie de pelvitrainer artesanal) con el que resecabamos piezas de adenomectomía obtenidas previamente. Pero en mi curva de aprendizaje endoscópico no podré olvidar nunca la demostración del Dr. Jaupitre, su filmación cinematográfica de una RTU prostática me hizo comprender aspectos hasta entonces ininteligibles.

La aportación de D. Luis Cifuentes al conocimiento y tratamiento de los tumores vesicales es todavía moneda de curso legal. En mi estancia como Residente ésta fue, sin duda, uno de los pilares de mi formación urológica. Eran tiempos en que en foros urológicos nacionales este tema estaba algo confuso, hablar de carcinoma "in situ" o proscribir rotundamente la apertura vesical para la exéresis de los tumores vesicales era todavía una quimera, pero en la Clínica de la Concepción era algo cotidiano. El magnífico trabajo de D.Luis, publicado en Journal d'Urologie et Nephrologie en 1971 sobre "Statistique de 1000 tumeurs vesicales" creo que sancionó la situación y definió posturas aún vigentes.

Si en lo urológico la figura del Dr.Cifuenes es algo tan contrastado que no merece la pena ahondar más, su vertiente social y humanística es quizás algo más desconocida, pero no por ello menos interesante. Llegar a la Clínica de la Concepción como Residente en 1966 fue para mí una auténtica conmoción. Era un Hospital moderno, como hoy los entendemos, y todavía vivía el Profesor Jiménez Diaz, rodeado de un elenco de figuras científicas de renombre, formadas bajo su dirección y la influencia de Universidades y Hospitales Norteamericanos. Aquel ambiente y aquellas Sesiones Anatomoclínicas de los sábados por la mañana dejaron huella en toda una generación.

En ese contexto conocí a D.Luis. Su distinción y cierta frialdad inicial imponían un gran respeto que pronto se transformó en admiración. De él dimanaba una gran autoridad, ejercida sin autoritarismo, con esa elegancia personal que siempre le caracterizó y que hacía posible que sus sugerencias y enseñanzas, nunca impositivas, nos alcanzaran con facilidad.

El Servicio de Urología de la Clínica de la Concepción se componía de un staff no muy numeroso, pero sí muy representativo. Su estructura era algo singular. Existía junto a la Jefatura de Servicio una figura especial, la de Jefe Asociado, que en este caso era bicéfala. Por un lado estaba D.Victoriano Molina, auténtico depositario de la Historia urológica del Madrid de la primera mitad del siglo XX. Cuántas historias nos contó y cuántas cosas aprendimos pasando consulta a su lado. Además, como valenciano de origen, tuvo conmigo una particular deferencia y afecto.

El otro Jefe Asociado era Carlos Alférez, quien para mí, quirúrgicamente fue una verdadera revelación, fue mi primer maestro quirúrgico. Su aportación a la cirugía urológica moderna dudo que haya sido lo suficientemente reconocida, pero los que tuvimos la fortuna de tenerle cerca no le podremos olvidar.

Seguía el escalafón y aparecía como Asociado Enrique García de la Peña, triste y prontamente desaparecido. Qué podría contaros de una persona tan entrañable como Enrique. Contactaba directamente con los Residentes prestándote su ciencia, bien estructurada y digerida, y además te ofrecía su amistad y su paternal consejo.

Completaba el staff Remigio Vela Navarrete, en aquel entonces recién llegado de California, 
aportándonos una ráfaga de modernidad y empuje sorprendente. No podré olvidar nunca aquellas investigaciones, con punciones renales y medición de presiones en la vía urinaria superior, con utillajes hábilmente improvisados; ni tampoco concepciones novedosas sobre quimioterapia antimicrobiana. De su mano gozamos de la presencia del Dr.Kaufman, en su año sabático, con magníficas participaciones en nuestras Sesiones Clínicas y en las no menos magníficas sesiones quirúrgicas sobre cirugía vasculo-renal.

En ese tiempo completaban el equipo el Dr. Escudero Barrilero como Residente senior, que compartió una temporada con nosotros antes de su incorporación a La Paz y los Residentes de mi promoción: el Dr. Cerrud de Panamá y el Dr.Cifuentes de Castro, hijo de D. Luis, y en una promoción posterior, el Dr. Antonio Berenguer.

Los periodos de residencia en aquella época, previa al MIR actual, no estaban establecidos. En La Fundación Jiménez Diaz eran de tres años. En ese insignificante periodo de tiempo tuve la oportunidad de acercarme a la figura humana del Dr.Cifuentes, quizás ayudado por el contacto con su hijo, con quien compartí una gran camaradería y afecto durante toda nuestra residencia.

De sobra es conocida la riqueza humanística de D.Luis, ya se han comentado en otras semblanzas sus aficiones literarias y deportivas. La música era una de sus pasiones y especialmente al piano era un intérprete nada despreciable. De manera casual me identifiqué mucho con él en este aspecto, cuando un día, en la sesión de lavado previa a una intervención quirúrgica, canturreaba una melodía y yo cometí la imprudencia o temeridad de preguntarle si le gustaba Brahms. Me miró, tuve la sensación de que lo hacía por primera vez, y lo cierto es que a partir de ese día tomó buena conciencia de mí. Posteriomente y junto a Luis Cifuentes hijo tuve la gran oportunidad de asistir a muchos conciertos de la Orquesta Nacional en el Teatro Real, obviamente con el abono de D.Luis.

En ese entorno conocí a personalidades de la talla de D. Pedro Laín Entralgo, Xavier Zubiri, el Maestro Rodrigo y otros intelectuales para mí desconocidos en aquel momento, que eran amigos personales del Dr.Cifuentes y que saluban a Luis hijo como alguien de la familia. Estos privilegios musicales comportaban cierto riesgo, te obligaban a prestar mucha atención durante el concierto, cuando no a documentarte sobre el mismo. No era de extrañar que durante una intervención quirúrgica, D.Luis te examinara sobre el último acontecimiento musical, poniéndote amablemente en aprietos mientras hacía relucir su erudición musical.

He dejado correr recuerdos a vuelapluma a riesgo de aburrirles. Recuerdos de una época urológica pasada que, aún corta en el tiempo, ha supuesto una presencia constante en mi vida profesional. En D.Luis encontré siempre disponibilidad, ayuda y consejo. De él conservaré siempre su mejor enseñanza: amor a la profesión tanto en su rigor científico como en su interés por el enfermo. 